\title{
Six-month performance of restorations produced with the ethanol-wet-bonding technique: a randomized trial
}

\section{Maurício Yugo de SOUZA(a) Ana Luiza Barbosa JUREMA(a) Taciana Marco Ferraz CANEPPELE(a) Eduardo BRESCIANI(a)}

(a) Universidade Estadual Paulista - Unesp, Institute of Science and Technology, Department of Restorative Dentistry, São José dos Campos, SP, Brazil.

Declaration of Interests: The authors certify that they have no commercial or associative interest that represents a conflict of interest in connection with the manuscript.

\section{Corresponding Author:}

Eduardo Bresciani

E-mail: eduardo.bresciani@unesp.br

Submitted: January 16, 2019

Accepted for publication: May 20, 2019

Last revision: May 22, 2019

\begin{abstract}
This double-blind randomized controlled clinical trial evaluated the effectiveness of dentin pretreatment with $100 \%$ ethanol (EWBT - ethanol wet bonding technique) and different adhesive protocols in noncarious cervical lesions (NCCL) after 6 months. Patients presenting at least one NCCL were included. NCCLs $(n=148)$ were randomly assigned to 4 groups: NE (Non-EWBT + three-step etch-and-rinse (Scotchbond Multi Purpose, 3M ESPE [MP]), E (EWBT + MP); EB (EWBT + [Bond third step of MP]), and EU (EWBT + universal adhesive (Single Bond Universal, 3M ESPE). Conventional acid-etching (Condac 37\%, FGM) and nanohybrid resin composite (Z350, 3M ESPE) were used. Trained and calibrated examiners $($ Kappa $=0.61)$ evaluated the restorations at baseline (7 days) and 6-month recall using the USPHS modified criteria. Data were subjected to Chi square $(\alpha=0.05)$. Differences in the success rate were found for the treatments $(p=0.003)$. EB presented the lowest success rate compared with the other groups $(p<0.02)$. No significant differences were detected among NE, E, and EU ( $p>0.49$ ). The survival rates were $97.23 \%, 97.30 \%, 78.95 \%$, and $97.30 \%$ for $\mathrm{NE}, \mathrm{E}, \mathrm{EB}$, and $\mathrm{EU}$, respectively. Regarding postoperative sensitivity, a significant reduction was found for groups $E(p=0.027)$ and EU $(p<0.01)$ after 6 months. After 6 months, EWBT associated to the hydrophobic adhesive system had the highest failure rate.
\end{abstract}

Keywords: Dentin; Ethanol; Adhesives; Tooth Abrasion.

\section{Introduction}

Dental tissues undergo different responses to acid-etching procedures ${ }^{1}$ and consequently to different adhesion patterns. For enamel, adhesion is facilitated because of the predominance of hydroxyapatite crystals and the consequent adequate formation of resin microtags. ${ }^{1,2}$ However, dentin consists of predominantly organic components, mainly collagen fibers, extension of odontoblasts, and dentinal fluid, which leads to a more variable and challenging bonding procedure.,3,4

A meta-analysis ${ }^{5}$ indicated that the best adhesion results to dentin were observed with the use of 2-step self-etch (moderate $\mathrm{pH}$ ) and 3-step etch-and-rinse adhesives. The authors also concluded that additional studies are required to improve dental adhesion. Although new dental adhesives have been introduced, including adhesives named "universal" 
or "multi-mode," resin restorations may still fail after a short lifespan because of degradation of the adhesive interface. ${ }^{6}$ Universal adhesives are adaptable, as they can be applied to wet or dry dentin and with both self-etch and etch-and-rinse protocols. ${ }^{3}$ In addition to improvements in the adhesive, some additional measures proposed to minimize interface degradation include dentin pretreatment, ${ }^{78}$ addition of different chlorhexidine concentrations to adhesives, ${ }^{7}$ formulation of experimental adhesives, ${ }^{9}$ use of matrix metalloprotease (MMPs) inhibitors, ${ }^{10}$ and the ethanol wet bonding technique (EWBT). ${ }^{11}$

The EWBT might extend the longevity of resin-dentin bonding if improved resin monomer infiltration and the consequent improved formation of the hybrid layer occurs..$^{12}$ Ethanol has a higher solvent ability and lower hydrogen bonding capacity than water. In the EWBT, it is used to dehydrate demineralized collagen fibrils chemically, creating a relatively hydrophobic dentin collagen matrix, which decreases the interface hydrolysis associated with water removal from the substrate. ${ }^{12}$ Two protocols have been reported for applying the EWBT: progressive water substitution, in which dentin ethanol saturation is obtained using increasing ethanol concentrations (takes about 3 to $4 \mathrm{~min}^{12}$; and a simplified protocol, where dehydration occurs with a single 1-minute application of $100 \%$ ethanol. ${ }^{13}$

Because of the high volatility of ethanol. The technique is sensitive; moreover ethanol does not completely displace water from dentin, a fact that may hinder the infiltration of hydrophobic adhesives. ${ }^{11}$ In vitro data suggest that the formed hybrid layer is less hydrophilic and more resistant to long-term hydrolytic degradation caused by water. The EWBT might improve longevity by effectively protecting the collagen. ${ }^{14}$ Few clinical studies have evaluated the EWBT as a dentin pretreatment. ${ }^{15,16}$ The use of ethanol has been evaluated with a modified progressive technique ${ }^{16}$ and by using two coats of hydrophobic bonding resin, ${ }^{15}$ with no significant differences because of the technique in these two clinical studies. In another study, a formulated experimental hydrophobic adhesive containing ethanol in its hydrophobic primer composition resulted in acceptable performance. ${ }^{17}$ The primer solution in that study was prepared by diluting an experimental hydrophobic adhesive in absolute ethanol up to $50 \%$ weight. ${ }^{17}$ To the best of the authors' knowledge, only one report on the clinical use of the EWBT with a commercially available hydrophobic adhesive has been published..$^{15}$ Moreover, only one study evaluated the cytotoxicity of the EWBT on human pulp cells; the authors concluded that it does not increase pulpal damage when compared with water-wet bonding after 48 hours. ${ }^{18}$

Non-carious cervical lesions (NCCLs) represent cervical tooth wear not associated with dental caries. These lesions may have different extensions, shapes (wedge, flat, concave, or acute angle) and depths. ${ }^{19}$ The restoration of NCCLs remains a challenge for clinicians, since retention loss can vary from $0 \%$ to $50 \%{ }^{20}$ For this reason, this type of cavity is the most appropriate for testing tooth adhesion in clinical trials. Factors responsible for restoration loss include the difficulty of adhesion between substrate and materials, the degree of dentin sclerosis, and the adequate establishment of the hybrid layer. ${ }^{20}$ In addition, both mechanical and non-mechanical factors decrease the longevity of restorations for NCCLs, including microshear forces during mastication. ${ }^{20}$

Based on the presented information and regarding the problems associated with dentin adhesion, possible dentin pretreatments that favor dentin adhesion should be assessed with well-designed clinical studies. ${ }^{5} \mathrm{~A}$ recent systematic review emphasized the need for clinical trials to determine the best dentin pretreatment. ${ }^{5}$ Therefore, the purpose of this clinical study was to evaluate the effectiveness of dentin pretreatment with $100 \%$ ethanol on the restoration of NCCLs using different adhesive protocols. The null hypothesis was that the ethanol wet bonding technique in association with different adhesive protocols does not influence the success of NCCL restorations overtime.

\section{Methodology}

\section{Ethics}

The local Institutional Review Board approved the present study (protocol number: 2.022.383). The study was also registered in the clinical trials registry database REBEC (http://www.ensaiosclinicos.gov. br) under protocol RBR-5hncr3. 


\section{Sample size calculation}

For this study, the sample size was calculated using an online statistical website - Sealed Envelope Ltda (www.sealedenvelop.com). For power calculation, equivalence trial function under binary outcome was selected, and the following parameters were chosen: $\alpha=5 \%$, power at $80 \%$, success of control and experimental group at $96 \%$, and limit of equivalence at $15 \%{ }^{21}$ Sample size was estimated at 30 restorations per group. Considering the possible loss of experimental units, a further five restorations were planned for each group, a total of 35 restorations per group and 140 restorations in total.

\section{Inclusion and exclusion criteria}

The inclusion criteria for patient selection were as follows: minimum age of 18 years; presence of at least one NCCL cavity in permanent canines or premolars; lesion depth and cervical width of $1 \mathrm{~mm}$ at minimum; presence of the antagonist and adjacent teeth; vital pulp and absence of painful symptoms; NCCL with no previous restorative treatment; and good oral health and absence of periodontal disease.

The exclusion criteria for selection were as follows: teeth with cervical caries lesions and patients with systemic diseases (e.g., gastroesophageal reflux) or allergies to the materials used; presence of deleterious habits or bruxism; and use of removable prostheses with clamps on the target teeth.

For this study, 67 participants met the inclusion criteria, signed the informed consent and were thus included (Figure 1).

\section{Study design}

This randomized controlled clinical trial followed CONSORT guidelines. ${ }^{22}$ As soon as the patient arrived at the clinic, the teeth were chosen for this clinical trial following the inclusion and exclusion criteria

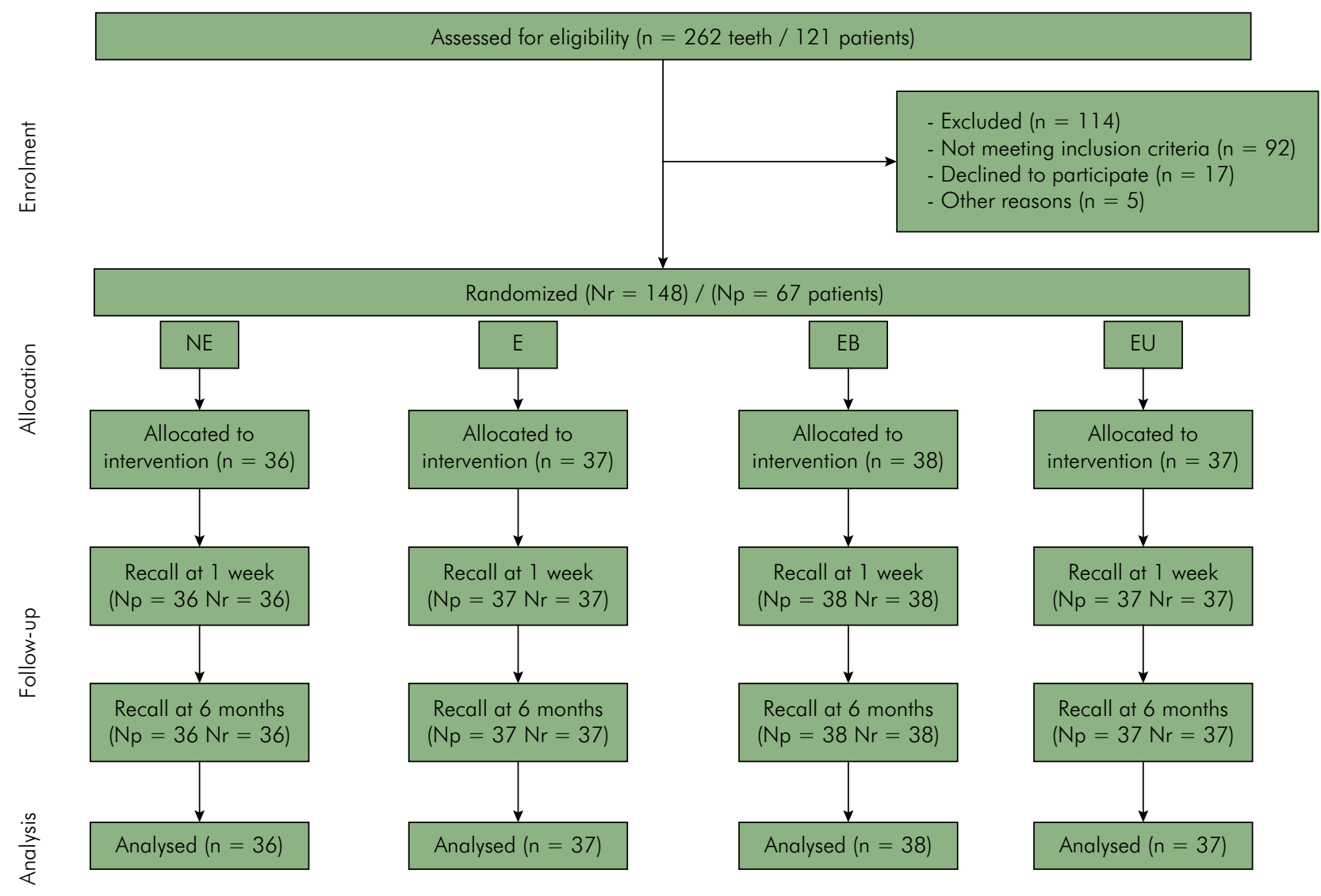

Figure 1. Flowchart including patient selection, restorations performed, and evaluation phase. 
and the informed consent form was signed. Prior to the restorative procedure, a person not involved in this clinical trial generated a randomization sequence of treatments for each patient, considering the four protocols. For patients receiving more than one treatment, in case more than one tooth was included in the study, treatments were allocated following a crescent tooth number (international tooth numbering system). Each patient received at least one and a maximum of four restorations; no patient received duplicate treatments. Thus, the treatments were allocated randomly for the included NCCLs.

\section{Restorative procedure}

All participants underwent professional pumice prophylaxis using a polishing brush. Isolation was then done with a lip retractor, cotton rolls, gingival displacement cord, and a saliva ejector. A bevel was not placed before restoring the lesion.

All cavities were conditioned with $37 \%$ phosphoric acid (Condac, FGM, Brazil) for $15 \mathrm{~s}$, followed by rinsing for $15 \mathrm{~s}$ and drying with absorbent paper. Lesions allocated under the EWBT protocol received 100\% ethanol, actively applied for $60 \mathrm{~s}$ with a microbrush. The adhesive systems were then applied, following the groups:

a. Control Group - NE: Non-EWBT [NE] + threestep etch-and-rinse (Scotchbond Multi Purpose, 3M ESPE [MP]); primer was applied to etched substrate and gently dried for $5 \mathrm{~s}+$ bond was actively applied for $20 \mathrm{~s}$, followed by a gentle blow of air for $5 \mathrm{~s}$ and light polymerizing for $10 \mathrm{~s}$.

b. E: EWBT [E] + three-step etch-and-rinse (Scotchbond Multi Purpose, 3M ESPE); 100\% ethanol was actively applied for $60 \mathrm{~s}+$ primer was applied to etched substrate and gently dried for $5 \mathrm{~s}+$ bond was actively applied for $20 \mathrm{~s}$, followed by a gentle blow of air for $5 \mathrm{~s}$ and light polymerizing for $10 \mathrm{~s}$.

c. EB: EWBT [E] + Bond (Scotchbond Multi Purpose, 3M ESPE) [B] (third step - Hydrophobic adhesive); $100 \%$ ethanol was actively applied for $60 \mathrm{~s}+$ bond was actively applied for $20 \mathrm{~s}$, followed by a gentle blow of air for $5 \mathrm{~s}$ and light polymerizing for $10 \mathrm{~s}$. d. EU: EWBT [E] + Universal adhesive (Scotchbond Universal, 3M ESPE) [U] (Hydrophilic);100\% ethanol was actively applied for $60 \mathrm{~s}+$ universal adhesive was actively applied for $20 \mathrm{~s}$, followed by a gentle blow of air for $5 \mathrm{~s}$ and light polymerizing for $10 \mathrm{~s}$.

Filtek Z350 XT (3M ESPE, Sumaré, Brazil) was used with an incremental technique for the restorations. Each increment of $2 \mathrm{~mm}$, maximum, was polymerized for $20 \mathrm{~s}$. The increments were initially placed on the incisal wall and then on the gingival wall. Most of restorations were completed with 2 increments. For all restorative procedures the light polymerizing was performed with an LED device with a power density of $900 \mathrm{~mW} / \mathrm{cm}^{2}$. Finishing was performed with fine finishing diamond rotary instruments (KG Sorensen, São Paulo, SP, Brazil). After 7 days, the restoration was polished with abrasive discs (Sof-Lex ${ }^{\mathrm{TM}}$ Pop-On, 3M ESPE, MN, USA).

\section{Periods and evaluation criteria}

The restorations were evaluated by two calibrated examiners (interexaminer agreement of $81 \%$, Kappa $0.61)$ not involved with the restorative procedures. Evaluations were performed at baseline (7 days) and after 6 months according to USPHS modified criteria (Figure 2). The patients and examiners were blind to the study parameters.

\section{Statistical analysis}

All data were analyzed using the chi-square test to verify the distribution of the success rate and postoperative sensitivity among groups. The level of significance was set at $5 \%$.

\section{Results}

The demographics of the study participants are shown in Table 1 . The participants were evenly distributed into groups with regard to sex, age, restored tooth, and the presence of wear facets in relation to restoration success or failure. Failures were detected only for the retention parameter. Differences in success rates were detected among all groups (chi-square; $p=0.003$ ). EB presented lower success rates when compared with all tested adhesive 


\begin{tabular}{|c|c|}
\hline SCORES & USPHS modified criteria \\
\hline \multicolumn{2}{|r|}{ Retention } \\
\hline Alfa (A) & No restorative material loss \\
\hline Charlie (C) & Partial or complete loss of restorative material \\
\hline \multicolumn{2}{|r|}{ Marginal discoloration } \\
\hline Alfa (A) & No discoloration between tooth structure and restorative material \\
\hline Bravo (B) & Marginal discoloration which can be polished away \\
\hline Charlie (C) & Discoloration in interface restorative material and tooth, no able to polish \\
\hline \multicolumn{2}{|r|}{ Marginal adaptation } \\
\hline Alfa (A) & Closely adapted, no detectable margin \\
\hline Bravo (B) & Detectable marginal discrepancy clinically acceptable \\
\hline Charlie (C) & Marginal crevice, clinically unacceptable \\
\hline Delta (D) & Mobile restoration, partially or totally fractured \\
\hline \multicolumn{2}{|r|}{ Secondary caries } \\
\hline Alfa (A) & No caries present \\
\hline Charlie (C) & Caries present \\
\hline \multicolumn{2}{|r|}{ Anatomic form } \\
\hline Alfa (A) & Continuous, well contoured \\
\hline Bravo (B) & Slight discontinuity or under contoured without dentin exposure, clinically acceptable \\
\hline Charlie (C) & Discontinuous, sever under contoured, with dentin exposure, clinically unacceptable \\
\hline \multicolumn{2}{|r|}{ Post-operative sensitivity } \\
\hline Alfa (A) & No post-operative \\
\hline Bravo (B) & Sensitive but with intensity decreasing \\
\hline Charlie (C) & Constant sensitivity, without intensity decreasing \\
\hline \multicolumn{2}{|r|}{ Surface texture } \\
\hline Alfa (A) & Texture such as enamel \\
\hline Bravo (B) & Texture such as resin composite \\
\hline Charlie (C) & Surface with pores or cracks, with dental pick retention \\
\hline
\end{tabular}

Figure 2. USPHS modified criteria.

protocols: $E B$ versus $\mathrm{NE}(\mathrm{p}=0.002), \mathrm{EB}$ versus $\mathrm{E}$ $(p=0.025)$, and EB versus EU ( $p=0.023)$. However, no significant differences were detected for other comparisons: NE versus $E(p=0.496)$, NE versus $\mathrm{EU}(\mathrm{p}=1.000)$, E versus EU ( $p=0.497)$. The survival rates were $97.23 \%, 97.30 \%$, $78.95 \%$, and $97.30 \%$, for NE, E, EB, and EU, respectively (Table 2).

Overall, tooth sensitivity was less after 6 months in comparison with the baseline observations ( $p<0.001$ ). A significant reduction in postoperative sensitivity after 6 months was detected for $\mathrm{E}(\mathrm{p}=0.027)$ and $\mathrm{EU}$ $(p<0.001)$. (Table 2). For other criteria, no significant differences $(p>0.05)$ were found.

\section{Discussion}

Complete removal of water from the dentin is not possible with the adhesive systems, leading to the dilution of monomers and water sorption of the adhesive layer during aging, with consequent hydrolysis. ${ }^{15,23}$ In order to minimize the hybrid layer and unprotected collagen hydrolysis overtime, the EWBT approach has been advocated for several reasons. The EWBT might remove and replace free and loosely bound water around the orifice of the dentin tubules and within the collagen microfibrils. ${ }^{23,24}$ However, the water is not completely removed from 
Six-month performance of restorations produced with the ethanol-wet-bonding technique: a randomized trial

Table 1. Demographics of the studied population. Distribution into studied groups by sex, age, restored teeth, and the frequency of wear facets in relation to restoration success or failure.

\begin{tabular}{|c|c|c|c|c|}
\hline Variable & $\mathrm{NE}$ & E & EB & EU \\
\hline Men & 19/36 (52.77\%) & $23 / 37(62.16 \%)$ & 18/38 (47.37\%) & $15 / 37$ (40.54\%) \\
\hline Women & $17 / 36$ (47.23\%) & $14 / 37$ (37.83\%) & $20 / 38$ (52.63\%) & $22 / 37$ (59.45\%) \\
\hline Age (years) & 55.75 & 53.21 & 52.60 & 55.43 \\
\hline Maxillary canine & 4/148 (2.70\%) & 4/148 (2.70\%) & 7/148 (4.73\%) & $3 / 148$ (2\%) \\
\hline Mandibular canine & $2 / 148(1.35 \%)$ & $2 / 148$ (1.35\%) & $1 / 148$ (0.67\%) & 0/148 (0\%) \\
\hline Maxillary premolar & $10 / 148$ (6.75\%) & 13/148 (8.78\%) & $12 / 148$ (8.10\%) & $10 / 148(6.75 \%)$ \\
\hline Mandibular premolar & $21 / 148(14.19 \%)$ & $18 / 148(12.16 \%)$ & $18 / 148(12.16 \%)$ & $24 / 148(16.21 \%)$ \\
\hline \multicolumn{5}{|l|}{ Tooth wear facet } \\
\hline \multicolumn{5}{|l|}{ Presence } \\
\hline Success & 14 & 19 & 10 & 19 \\
\hline Loss & 3 & 1 & 6 & 0 \\
\hline \multicolumn{5}{|l|}{ Absence } \\
\hline Success & 19 & 15 & 15 & 18 \\
\hline Loss & 0 & 2 & 7 & 0 \\
\hline
\end{tabular}

Table 2. Distribution of number of restorations and percentage (\%) according to each evaluated criteria at 7 days and 6 months.

\begin{tabular}{|c|c|c|c|c|c|c|c|c|c|}
\hline \multirow{2}{*}{ Criteria } & \multirow{2}{*}{ Scores } & \multicolumn{4}{|c|}{ Baseline - 7 Days } & \multicolumn{4}{|c|}{6 Months } \\
\hline & & NE & EU & EB & $E$ & NE & EU & EB & $\mathrm{E}$ \\
\hline \multirow{2}{*}{ Retention } & Alfa & 36 (100\%) & 37 (100\%) & 38 (100\%) & 37 (100\%) & $35(97.23 \%)^{a}$ & $36(97.30 \%)^{a}$ & $30(78.95 \%)^{b}$ & $36(97.30 \%)^{a}$ \\
\hline & Charlie & 0 & 0 & 0 & 0 & $1(2.77 \%)$ & $1(2.70 \%)$ & 8 (21.05\%) & $1(2.70 \%)$ \\
\hline \multirow{3}{*}{$\begin{array}{l}\text { Marginal } \\
\text { discoloration }\end{array}$} & Alfa & 36 (100\%) & 37 (100\%) & 38 (100\%) & 37 (100\%) & 32 (88.89\%) & 33 (89.19\%) & 30 (78.95\%) & $36(97.30 \%)$ \\
\hline & Bravo & 0 & 0 & 0 & 0 & $3(8.34 \%)$ & $3(8.11 \%)$ & 0 & 0 \\
\hline & Charlie & 0 & 0 & 0 & 0 & 0 & 0 & 0 & 0 \\
\hline \multirow{3}{*}{$\begin{array}{l}\text { Marginal } \\
\text { adaptation }\end{array}$} & Alfa & 35 (97.23\%) & 37 (100\%) & 37 (97.37\%) & 37 (100\%) & 32 (88.89\%) & 32 (86.49\%) & $28(73.68 \%)$ & 34 (89.19\%) \\
\hline & Bravo & 1 (2.77\%) & 0 & 1 (2.63\%) & 0 & $3(8.34 \%)$ & 4 (10.81\%) & 2 (5.27\%) & 4 (10.81\%) \\
\hline & Charlie & 0 & 0 & 0 & 0 & 0 & 0 & 0 & 0 \\
\hline \multirow{2}{*}{$\begin{array}{l}\text { Secondary } \\
\text { caries }\end{array}$} & Alfa & 36 (100\%) & 37 (100\%) & 38 (100\%) & 37 (100\%) & $35(97.23 \%)$ & $36(100 \%)$ & 30 (78.95\%) & $36(97.30 \%)$ \\
\hline & Charlie & 0 & 0 & 0 & 0 & 0 & 0 & 0 & 0 \\
\hline \multirow{3}{*}{$\begin{array}{l}\text { Anatomic } \\
\text { form }\end{array}$} & Alfa & 36 (100\%) & 37 (100\%) & 38 (100\%) & 37 (100\%) & 35 (97.23\%) & 35 (94.60\%) & 30 (78.95\%) & 35 (94.60\%) \\
\hline & Bravo & 0 & 0 & 0 & 0 & 0 & 1 (2.70\%) & 0 & $1(5.40 \%)$ \\
\hline & Charlie & 0 & 0 & 0 & 0 & 0 & 0 & 0 & 0 \\
\hline \multirow{3}{*}{$\begin{array}{l}\text { Postoperative } \\
\text { sensitivity }\end{array}$} & Alfa & 27 (75\%) & $30(81.08 \%)$ & 28 (23.68\%) & 30 (81.08\%) & 32 (88.89\%) & 35 (94.60\%)* & 28 (73.68\%) & $35(94.60 \%)^{*}$ \\
\hline & Bravo & 8 (22.22\%) & 7 (18.92\%) & 9 (76.32\%) & 7 (18.92\%) & $3(8.34 \%)$ & $1(2.70 \%)$ & $2(5.27 \%)$ & $1(5.40 \%)$ \\
\hline & Charlie & $1(2.77 \%)$ & 0 & 0 & 0 & 0 & 0 & 0 & 0 \\
\hline \multirow{3}{*}{$\begin{array}{l}\text { Surface } \\
\text { texture }\end{array}$} & Alfa & 36 (100\%) & 37 (100\%) & 38 (100\%) & 37 (100\%) & 31 (86.11\%) & 31 (83.79\%) & $26(68.42 \%)$ & 31 (83.79\%) \\
\hline & Bravo & 0 & 0 & 0 & 0 & 4 (11.12\%) & 5 (13.51\%) & 4 (10.53\%) & 5 (13.51\%) \\
\hline & Charlie & 0 & 0 & 0 & 0 & 0 & 0 & 0 & 0 \\
\hline
\end{tabular}

Different superscript letters indicate differences on retention rates at the 6 -month recall $(p<0.05)$; Asterisks indicate groups presenting significant reduction of post-operative sensitivity at the 6-month recall in relation to the baseline $(p<0.05)$. 
the dentin substrate. ${ }^{11}$ Questions regarding the effect of the amount of remaining water on the bond strength with hydrophobic adhesives have been raised, and that issue has been evaluated in an in vitro study. ${ }^{25}$ The results were acceptable when hydrophilic adhesives were used with EBWT, possibly due to the combination of the remaining water in dentin and the water from the adhesive composition. The implementation of a new layer of water in a dehydrated dentin surface is questionable, but that association has been reported to be effective in in vitro conditions, warranting clinical investigations.

The EWBT approach also prevents phase separation of the adhesive, ${ }^{26}$ possibly improving long-term bond strength. ${ }^{27}$ In addition, the use of the EWBT might decrease the diameter of collagen fibrils and the matrix volume, consequently increasing the interfibrillar spaces and leading to greater impregnation of the adhesive system and hydrophobic monomers. ${ }^{24}$ The results from micro-Raman ${ }^{28}$ and two-photon laser confocal microscopy ${ }^{29}$ analyses indicated that the EWBT favors the relatively homogeneous distribution of methacrylates (BisGMA) in the interfibrillar spaces. This allows the formation of a hybrid layer with improved mechanical and bonding properties, since the greater the amount of hydrophobic infiltrated resin monomers, the greater the resindentin bonding strength. ${ }^{30}$ Improved hydrophobic monomer impregnation protects and encapsulates collagen fibers more efficiently, ${ }^{28}$ and it decreases both water sorption and the enzyme-catalyzed hydrolytic cleavage of collagen, ${ }^{12,24}$ increasing collagen rigidity, which contributes to the formation of a more effective hybrid layer. ${ }^{27}$ In spite of the reported benefits of using the EWBT, the inclusion of an extra step in the adhesive protocol is a disadvantage, as it adds to the clinical time and may increase technique sensitivity. The main challenge of dental adhesion, which is related to the dentin substrate, is still not solved. Thus, testing alternative protocols, even with additional steps is justified.

The null hypothesis that the ethanol-wet-bonding technique does not influence NCCL restoration success over time was partially accepted. The combination of hydrophilic adhesive systems and the EWBT was compared to the control group (NE), while the use of a commercially available hydrophobic adhesive associated with the EWBT resulted in lower success rates when compared with the other tested groups.

The three-step etch-and-rinse adhesive system was considered the gold standard in a systematic review $^{5}$, supporting its present use as the control group. Organic solvents within hydrophilic adhesive systems, such as acetone and ethanol, are preferred to water, as they encourage infiltration of resin monomers into collagen fibrils, resulting in better adhesive bonding. ${ }^{31}$ According to Mair and Padipatvuthikul, ${ }^{32}$ organic solvents displace water molecules within the dentin matrix and, because of their high evaporation capacity, facilitate the diffusion of monomers into demineralized dentin. However, the presence of residual solvent in the adhesive interface might result in disturbances in the polymerization reaction, which would reduce adhesion. The better the evaporation capacity, the lower the amount of residual solvent at the adhesive interface. ${ }^{33}$ Because the Single Bond Universal adhesive system also contains ethanol as a solvent, the EWBT may have facilitated the impregnation of resin monomers, resulting in stable bonding.

Although the increased permeability of monomers may increase toxicity potential and compromise the longevity of restorations, ${ }^{32}$ this was not observed in the present study during the evaluated period. Moreover, the EWBT may increase the absorption and degree of conversion of the resin monomers ${ }^{26}$ and produce a hydrophobic collagen matrix with improved sealing, even if a hydrophilic adhesive is used. In addition, the EWBT reduces the sorption of water and collagen hydrolysis, making the hybrid layer more stable. ${ }^{34}$ All those reported advantages might explain the positive results obtained with the hydrophilic adhesive used in the present study. Longer evaluation periods may reveal a possible benefit of associating the EWBT with the hydrophobic adhesive systems tested.

Improved bonding between hydrophobic adhesives and dentin has been reported with EWBT, possibly because of improved water removal from the collagen matrix and proper collagen encapsulation, forming a less hydrophilic hybrid layer. ${ }^{17,35}$ However, clinical trials evaluating the EWBT did not show significant differences after 12 or 18 months, with retention rates 
for the EWBT at $91.67 \%$ and $93.55 \% .16,36$ Technique differences in those studies are related to the use of a formulated hydrophobic primer (hydrophobic bond diluted in ethanol in a concentration of $10 \%$ or $50 \mathrm{w} \%$ ethanol) or the ethanol not being actively applied. ${ }^{12,15,16,36,37}$ Although no differences were detected when compared with the control groups, one study reported that the $91.7 \%$ success for the EWBT in comparison with the $100 \%$ success rate for the control could be related to the sensitivity of the EWBT. This sensitivity in association with the viscosity of commercially available hydrophobic adhesives might explain the present data. Combining the EWBT with hydrophobic adhesive led to reduced success rates when compared with those of the other groups (EB versus NE [ $p=0.002]$, EB versus $E$ $[p=0.025]$, and $E B$ versus $E U[p=0.023])$. The viscosity of the hydrophobic adhesive may have restricted monomer infiltration into the demineralized dentin, as studies using diluted hydrophobic monomers for application resulted in improved clinical success rates. ${ }^{15,36}$ The present study used commercially available hydrophobic monomers with the EWBT. Clinicians do not have access to diluted hydrophobic monomers, and the in vitro or in vivo results reported previously might not be reproducible as they depend on experimental materials.

For the universal adhesive, besides possible water removal from the dentin matrix and infiltration of resin monomers (Bis-GMA/TEGDMA), the interaction of 10-MDP functional monomer with calcium hydroxyapatite of the dentin ${ }^{38}$ might also support the obtained results. That interaction helps decrease the dissolution rate of the Ca-salt formed and helps maintain the durability of the bonded interface ${ }^{38}$ Longer-term evaluations are required to validate this statement. The effect of EWBT on the self-etching mode of universal adhesives might be explained by the ethanol application modifying the organic matrix of the smear layer, ${ }^{25}$ allowing crystals to be available for bonding with the adhesive system and possibly assisting the interdiffusion of the adhesive monomers in the smear layer and the collagen fibrils.

In addition, the combination of the EWBT and universal adhesives in the self-etch mode should be evaluated for possible interactions between the smear layer and the EWBT approach. Furthermore, clinical studies using self-etching adhesives with longer evaluation periods are needed. Limitations of this present clinical trial include that the restorations were not independent, the evaluation period was short, and some characteristics may have influenced the restorative treatment success, such as the thickness layer of the adhesives, adhesive viscosity, and wettability, in addition to the variable occlusion of the participants. For the participant occlusion, the distribution of failed and successful restorations was not related to the presence or absence of wear facets, suggesting that characteristic might have not influenced the results.

The value of short-term (6-month) recall information is unclear. Defining a better adhesive protocol with a dentin pretreatment might have affected the results. The importance of the present clinical trial relates to the fact that only one study evaluating the EWBT assessed the results using a commercially available product and mainly to the fact that the results were not favorable for the original technique at the very short-term presently reported.

\section{Conclusions}

The association between EWBT with commercially available hydrophobic adhesive system should be limited due to reduced restoration longevity. All hydrophilic adhesive systems presented greater success rate at this evaluation period.

\section{References}

\footnotetext{
1. Suda S, Tsujimoto A, Barkmeier WW, Nojiri K, Nagura Y, Takamizawa T, et al. Comparison of enamel bond fatigue durability between universal adhesives and two-step self-etch adhesives: effect of phosphoric acid pre-etching. Dent Mater J. 2018 Mar;37(2):244-55. https://doi.org/10.4012/dmi.2017-059
} 
2. Perdigâo J. Dentin bonding as a function of dentin structure. Dent Clin North Am. 2002;46(2):277-301. https://doi.org/10.1016/S0011-8532(01)00008-8

3. Perdigão J, Kose C, Mena-Serrano AP, De Paula EA, Tay LY, Reis A, et al. A new universal simplified adhesive: 18-month clinical evaluation. Oper Dent. 2014 Mar-Apr;39(2):113-27. https://doi.org/10.2341/13-045-C

4. Carrilho MR, Carvalho RM, Tay FR, Yiu C, Pashley DH. Durability of resin-dentin bonds related to water and oil storage. Am J Dent. 2005 Dec;18(6):315-9.

5. Peumans M, De Munck J, Mine A, Van Meerbeek B. Clinical effectiveness of contemporary adhesives for the restoration of non-carious cervical lesions. A systematic review. Dent Mater. 2014 Oct;30(10):1089-103. https://doi.org/10.1016/i.dental.2014.07.007

6. Pashley DH, Tay FR, Breschi L, Tiäderhane L, Carvalho RM, Carrilho M, et al. State of the art etch-and-rinse adhesives. Dent Mater. 2011 Jan;27(1):1-16. https://doi.org/10.1016/i.dental.2010.10.016

7. Vallabhdas AK, Kumar CN, Kabbinale P, Nayak R, Rajakumari M, Shilpa T. Evaluation of hybrid layer and bonding interface after water storage with and without the usage of $2 \%$ chlorhexidine: a scanning electron microscope study. J Contemp Dent Pract. 2018 Jan;19(1):52-9. https://doi.org/10.5005/ip-journals-10024-2211

8. Aggarwal V, Bhasin SS. Application of calcium silicate materials after acid etching may preserve resin-dentin bonds. Oper Dent. 2018 Sep/Oct;43(5):E243-52. https://doi.org/10.2341/17-306-L

9. Provenzi C, Collares FM, Cuppini M, Samuel SM, Alves AK, Bergmann CP, et al. Effect of nanostructured zirconium dioxide incorporation in an experimental adhesive resin. Clin Oral Investig. $2018 \mathrm{Jul}$;22(6):2209-18. https://doi.org/10.1007/s00784-017-2311-z

10. Hashimoto M, Hirose N, Kitagawa H, Yamaguchi S, Imazato S. Improving the durability of resin-dentin bonds with an antibacterial monomer MDPB. Dent Mater J. 2018 Jul;37(4):620-7. https://doi.org/10.4012/dmj.2017-209

11. Pashley DH, Tay FR, Carvalho RM, Rueggeberg FA, Agee KA, Carrilho M, et al. From dry bonding to water-wet bonding to ethanol-wet bonding. A review of the interactions between dentin matrix and solvated resins using a macromodel of the hybrid layer. Am J Dent. 2007 Feb;20(1):7-20.

12. Sadek FT, Braga RR, Muench A, Liu Y, Pashley DH, Tay FR. Ethanol wet-bonding challenges current anti-degradation strategy. J Dent Res. 2010 Dec;89(12):1499-504. https://doi.org/10.1177/0022034510385240

13. Sauro S, Toledano M, Aguilera FS, Mannocci F, Pashley DH, Tay FR, et al. Resin-dentin bonds to EDTA-treated vs. acid-etched dentin using ethanol wet-bonding. Part II: effects of mechanical cycling load on microtensile bond strengths. Dent Mater. 2011 Jun;27(6):563-72. https://doi.org/10.1016/i.dental.2011.02.010

14. Breschi L, Mazzoni A, Ruggeri A, Cadenaro M, Di Lenarda R, De Stefano Dorigo E. Dental adhesion review: aging and stability of the bonded interface. Dent Mater. 2008 Jan;24(1):90-101. https://doi.org/10.1016/j.dental.2007.02.009

15. Mortazavi V, Samimi P, Rafizadeh M, Kazemi S. A randomized clinical trial evaluating the success rate of ethanol wet bonding technique and two adhesives. Dent Res J (Isfahan). 2012 Sep;9(5):588-94. https://doi.org/10.4103/1735-3327.104878

16. Barros TAF, Araújo JF, Braga EMF, Souza PARS, Loretto SC, Souza Júnior MHSE. Ethanol-wet bonding technique: 18-month clinical evaluation. Int J Odontostomatol. 2016;10(2):267-76. https://doi.org/10.4067/S0718-381X2016000200013

17. Sadek FT, Castellan CS, Braga RR, Mai S, Tiäderhane L, Pashley DH, et al. One-year stability of resin-dentin bonds created with a hydrophobic ethanol-wet bonding technique. Dent Mater. 2010 Apr;26(4):380-6. https://doi.org/10.1016/j.dental.2009.12.009

18. Scheffel DL, Sacono NT, Ribeiro AP, Soares DG, Basso FG, Pashley D, et al. Immediate human pulp response to ethanol-wet bonding technique. J Dent. 2015 May;43(5):537-45. https://doi.org/10.1016/i.jdent.2015.02.014

19. Eliguzeloglu E, Eraslan O, Omurlu H, Eskitascioglu G, Belli S. The effect of cavity shape and hybrid layer on the stress distribution of cervical composite restorations. Eur J Dent. 2011 Apr;5(2):180-5.

20. Heintze SD, Ruffieux C, Rousson V. Clinical performance of cervical restorations-a meta-analysis. Dent Mater. 2010 Oct;26(10):993-1000. https://doi.org/10.1016/j.dental.2010.06.003

21. Reis A, Loguercio AD. A 36-month clinical evaluation of ethanol/water and acetone-based etch-and-rinse adhesives in non-carious cervical lesions. Oper Dent. 2009 Jul-Aug;34(4):384-91. https://doi.org/10.2341/08-117

22. Schulz KF, Altman DG, Moher D. CONSORT 2010 statement: updated guidelines for reporting parallel group randomised trials. BMJ. 2010 Mar;340 mar23 1:c332. https://doi.org/10.1136/bmi.c332

23. Osorio E, Toledano M, Aguilera FS, Tay FR, Osorio R. Ethanol wet-bonding technique sensitivity assessed by AFM. J Dent Res. 2010 Nov;89(11):1264-9. https://doi.org/10.1177/0022034510376403

24. Hosaka K, Nishitani Y, Tagami J, Yoshiyama M, Brackett WW, Agee KA, et al. Durability of resin-dentin bonds to water- vs. ethanolsaturated dentin. J Dent Res. 2009 Feb;88(2):146-51. https://doi.org/10.1177/0022034508328910

25. Souza MY, DI Nicoló R, Bresciani E. Influence of ethanol-wet dentin, adhesive mode of application, and aging on bond strength of universal adhesive. Braz Oral Res. 2018 Oct;32(0):e102. https://doi.org/10.1590/1807-3107bor-2018.vol32.0102

26. Liu Y, Tiäderhane L, Breschi L, Mazzoni A, Li N, Mao J, et al. Limitations in bonding to dentin and experimental strategies to prevent bond degradation. J Dent Res. 2011 Aug;90(8):953-68. https://doi.org/10.1177/0022034510391799 
Six-month performance of restorations produced with the ethanol-wet-bonding technique: a randomized trial

27. Tay FR, Pashley DH, Kapur RR, Carrilho MR, Hur YB, Garrett LV, et al. Bonding BisGMA to dentin: proof of concept for hydrophobic dentin bonding. J Dent Res. 2007 Nov;86(11):1034-9. https://doi.org/10.1177/154405910708601103

28. Shin TP, Yao X, Huenergardt R, Walker MP, Wang Y. Morphological and chemical characterization of bonding hydrophobic adhesive to dentin using ethanol wet bonding technique. Dent Mater. 2009 Aug;25(8):1050-7. https://doi.org/10.1016/i.dental.2009.03.006

29. Sauro S, Watson TF, Mannocci F, Tay FR, Pashley DH. Prevention of water contamination of ethanol-saturated dentin and hydrophobic hybrid layers. J Adhes Dent. 2009 Aug; 11(4):271-8.

30. Kim J, Gu L, Breschi L, Tjäderhane L, Choi KK, Pashley DH, et al. Implication of ethanol wet-bonding in hybrid layer remineralization. J Dent Res. 2010 Jun;89(6):575-80. https://doi.org/10.1177/0022034510363380

31. Ahn J, Jung KH, Son SA, Hur B, Kwon YH, Park JK. Effect of additional etching and ethanol-wet bonding on the dentin bond strength of one-step self-etch adhesives. Restor Dent Endod. 2015 Feb;40(1):68-74. https://doi.org/10.5395/rde.2015.40.1.68

32. Mair L, Padipatvuthikul P. Variables related to materials and preparing for bond strength testing irrespective of the test protocol. Dent Mater. 2010 Feb;26(2):e17-23. https://doi.org/10.1016/i.dental.2009.11.154

33. Salvio LA, Hipólito VD, Martins AL, Goes MF. Hybridization quality and bond strength of adhesive systems according to interaction with dentin. Eur J Dent. 2013 Jul;7(3):315-26. https://doi.org/10.4103/1305-7456.115416

34. Tjäderhane L, Nascimento FD, Breschi L, Mazzoni A, Tersariol IL, Geraldeli S, et al. Strategies to prevent hydrolytic degradation of the hybrid layer-A review. Dent Mater. 2013 Oct;29(10):999-1011. https://doi.org/10.1016/j.dental.2013.07.016

35. Huang X, Li L, Huang C, Du X. Effect of ethanol-wet bonding with hydrophobic adhesive on caries-affected dentine. Eur J Oral Sci. 2011 Aug;119(4):310-5. https://doi.org/10.1111/j.1600-0722.2011.00830.x

36. Araújo JF, Barros TA, Braga EM, Loretto SC, Souza PAS, Souza MHS. One-year evaluation of a simplified ethanol-wet bonding technique: a randomized clinical trial. Braz Dent J. 2013;24(3):267-72. https://doi.org/10.1590/0103-6440201302128

37. Nagpal R, Manuja N, Pandit IK. Effect of ethanol wet bonding technique on the durability of resin- dentin bond with contemporary adhesive systems. J Clin Pediatr Dent. 2015;39(2):133-42. https://doi.org/10.17796/jcpd.39.2.p14u4x3q14272452

38. Yokota Y, Fujita KN, Uchida R, Aida E, Aoki NT, Aida M, et al. Quantitative Evaluation of MDP-Ca Salt and DCPD after Application of an MDP-based One-step Self-etching Adhesive on Enamel and Dentin. J Adhes Dent. 2016;18(3):205-13. 